American Journal of Environmental Sciences 7 (3): 219-223, 2011

ISSN 1553-345X

(C) 2011 Science Publications

\title{
Role of Evaporation in Degrading the "Oil Lakes"
}

\author{
${ }^{1}$ Al Rashed Ahamad and ${ }^{2}$ Colin Barker \\ ${ }^{1}$ Department of Public Authority for Applied Education and Training, Kuwait \\ ${ }^{2}$ Department of Geosciences, University of Talsa, Oklahoma, USA
}

\begin{abstract}
Problem statement: Oil Spills are degraded by aerobic bacteria, water washing, evaporation and oxidation. In the absence of water the first two of these processes cannot operate. This is the situation in the low rainfall environment of the Kuwaiti desert where oil lakes still persist 20 years after the initial spills. The oils contain longer chain n-alkanes but have lost light ends and evaporation appears to be the dominant degradation mechanism. Approach: We have simulated evaporation of Kuwaiti oil (from Burgan field) at temperatures from $20-50^{\circ} \mathrm{C}$ and at various air flow rates. Results: Compositional changes monitored by gas chromatography show losses of volatile components $(<\mathrm{C} 8)$, including alkanes, aromatics and naphthenes. Normal alkanes are lost more rapidly than other hydrocarbon types with the same carbon numbers. Conclusion: Evaporation increases viscosity and density leading to compositional stratification. It seems likely that a devolatilized "skin" forms, protecting the underlying oil and decreasing the rate of evaporation. Oils degraded by evaporation show final compositions similar to those observed in the residual oil lakes.
\end{abstract}

Key words: Evaporation, oil spills, gas chromatographic, laboratory experiments, weight loss, degradation mechanism, compositional changes, during evaporation

\section{INTRODUCTION}

As a consequence of the 1991 Iraqi invasion of Kuwait considerable quantities of Oil were spilled in the desert. Twoney year's later "oil lakes" remnants still show relatively natural degration. Oil in the southern "oil lakes" was derived from the giant Burgan oil field to the east. Gas chromatographic analysis of Burgan oil (Fig. 1) shows the presence of light ends and a smooth distribution of normal alkanes up to approximately $\mathrm{nC} 32$. In contrast, oils from the southern lakes show a lack of compounds with less than about 14 carbon atoms, but abundant long chain n-alkanes (Fig. 2). Pristane/nC 17 and phytane/nC 18 ratios remain essentially the same as in the Burgan crude oil Comparison of these compositional differences permit inferences about the degradation processes operating in the Kuwait desert.

Natural oil spills can be degraded by several different processes, the most important being bacterial degradation, water washing, evaporationand photo oxidation (Corinan, 1984; Olajide and Ogbeifun, 2010; Palmer, 1993; Satoa et al., 1998; Obuekwe et al., 2008). Aerobic bacteria degrade oils when water, oxygen and nutrients are presentand remove compound types in a well-documented sequence starting with nalkanes 1, 2. The bacteria cannot live in the oil and require an aqueous phase. Liquid water is also needed for water washing to be effective. This degradation mechanism removes the most soluble components, which are the gasoline range hydrocarbons, especially the aromatics 3,4. Average rainfall in the Kuwait desert is only $155 \mathrm{~mm} /$ year 5 and there are no standing bodies of water. It seems unlikely that either biodegradation or water washing has had a major role in the degradation of Kuwait oils. In addition to being very dry the desert is extremely hot with temperatures reaching $>50^{\circ} \mathrm{C}$ $\left(>122{ }^{\circ} \mathrm{F}\right)$ in the summer months. This suggests that evaporation is likely to be an important process in modifying the composition of surface oil spills in the desert. Evaporation has been simulated in laboratory experiments.

Oil samples were collected from wells producing from the Burgan oil field and Stored in sealed glass containers. Samples from the "oil lakes" were taken and also stored in sealed glass containers.

\section{MATERIALS AND METHODS}

Evaporation weight-loss: Evaporative losses from crude oils were investigated using the simple apparatus shown in Fig. 3. Air was passed over the free surface of the oil sample and weight and composition monitored as a function of time. Temperature was controlled at 20, 30,40 , or $50^{\circ} \mathrm{C}$ by an external water bath and air velocity controlled with electrical fan and monitored with a ratometer to give flow rates of 200, 500 and $1000 \mathrm{round} / \mathrm{min}$. 


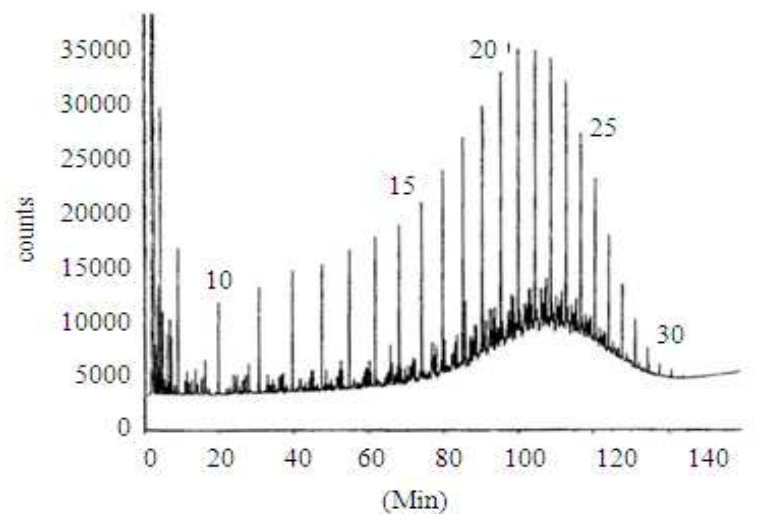

Fig. 1: Gas chromatogram of oil from the Burgan Oilfield, southeast Kuwait. Carbon number of selected normal alkancs are shown

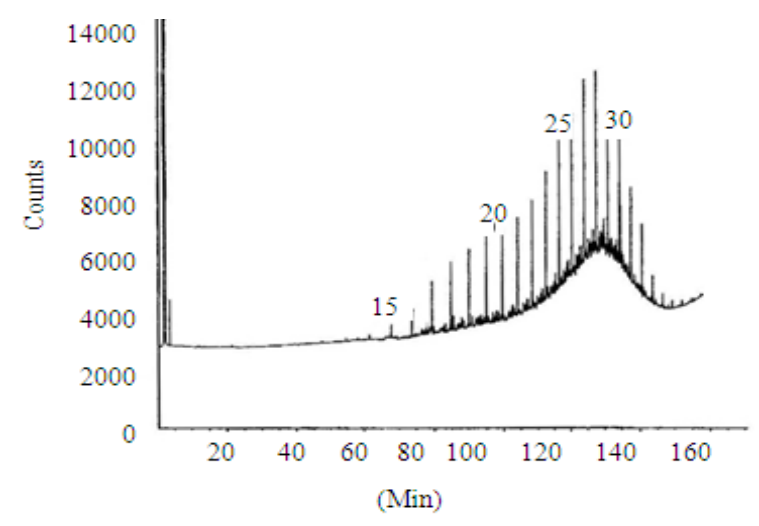

Fig. 2: Gas chromatogram of a sample taken from edge of one of the southern 'oil lakes', Kuwait. Carbon number of selected normal alkanes are shown

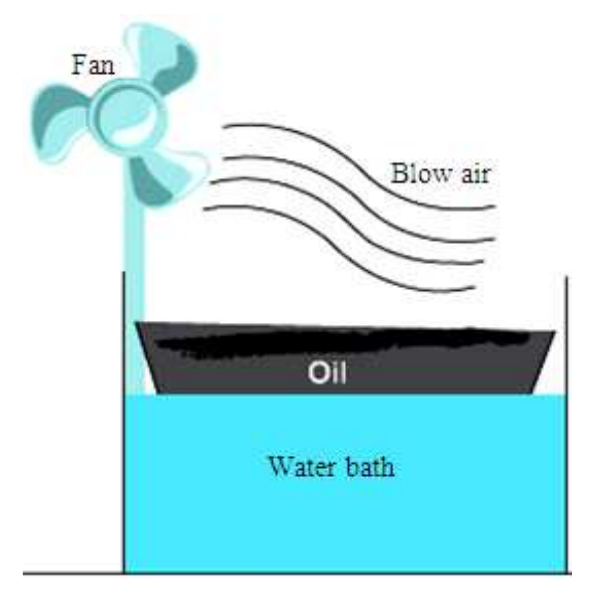

Fig. 3: Schematic diagram of the system used for the evaporation experiment
The rate of evaporative loss is initially rapid but decreases with time6. A typical Example for the Burgan crude oil (Fig. 4) shows this initial rapid weight loss and the subsequent decrease with time. In this particular example illustrating changes at $25^{\circ} \mathrm{C}$ and 1000 round/min, $13.07 \%$ is lost in the first $8 \mathrm{~h}$ and $25.68 \%$ is lost after $200 \mathrm{~h}$ when the experiment was terminated. At higher temperatures both the initial rate of loss and the percentage loss after is $200 \mathrm{~h}$ is higher. Figure 5 compares weight loss Through time for the Burgan oil at 25, 30, 40 and $50^{\circ} \mathrm{C}$ and Table 1 summarized weight losses after various time intervals for the four temperatures used in the experiments. Not surprisingly, evaporative losses are greater at higher air flows.

\section{RESULTS AND DISCUSSION}

Compositional changes during evaporation: Based on the results of the weight loss studies, airflow rates were kept constant at $1000 \mathrm{round} / \mathrm{min}$ for the determination of compositional changes and temperature controlled at $20,30,40$, or $50^{\circ} \mathrm{C}$. The apparatus shown in Fig. 3 was also used to investigate.

Compositional changes as evaporation progressed. 100 up oil samples were removed at intervals with a hypodermic syringe, diluted 2:1 with ethylene chloride and analyzed gas chromatographically. Gasoline range compounds and normal alkanes were identified by their relative retention times compared with authentic standards. Quantization was based on integrated peak areas.

For all combinations of temperature and air flow rate used in the laboratory experiments the smaller more volatile compounds were lost most rapidly. For molecules with more than approximately 15 carbon atoms there was no loss, even after $200 \mathrm{hrs,} \mathrm{which} \mathrm{was}$ the longest experimental run. This presented a convenient way of quantifying evaporative loss by using a long chain alkane as an effective internal standard. Normalc3 1 was selected. The choice was a compromise between reasonable peak size for a long chain and the fact that $\mathrm{nC} 30$ had a close eluting peak (see, for example, Fig. 1). Ratios of (peak area of gasoline range hydrocarbon)/ (peak area of nC3 1) were used to follow the progress of evaporation. Figure 6, for example, shows the decreasing concentration of 1000 round/min. This curve has the shape expect if Henry's Law controls the amount of the compound in the vapor phase and the vapor is removed at uniform time intervals. 
Am. J. Environ. Sci., 7 (3): 219-223, 2011

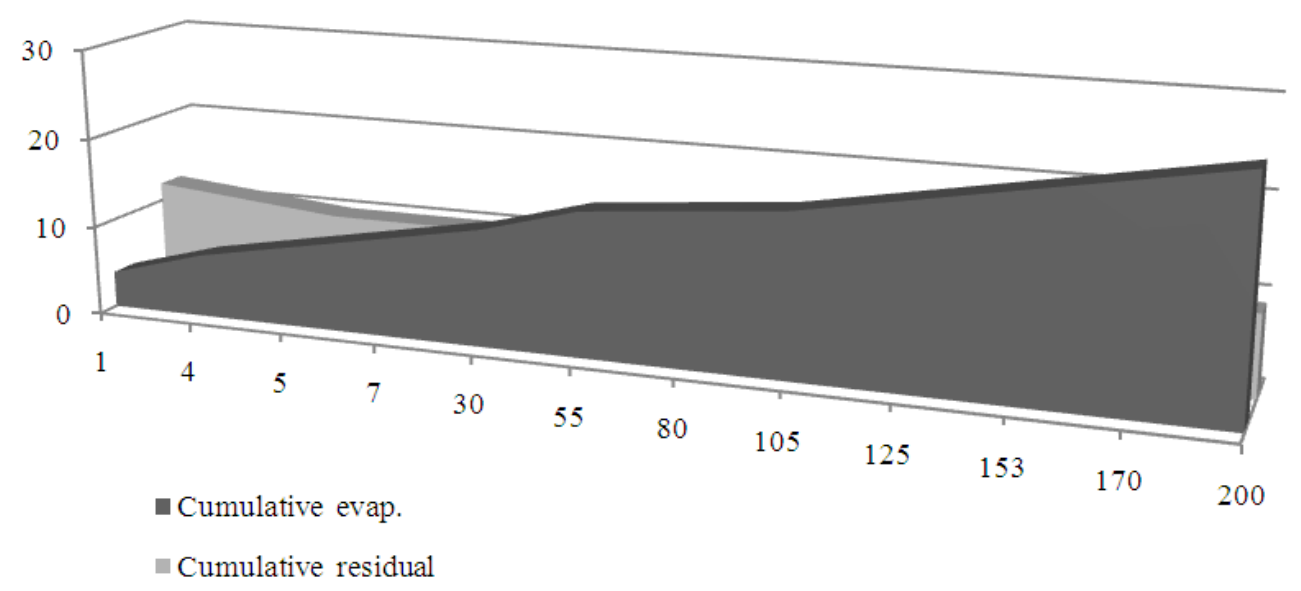

Fig. 4: Cumulative evaporative weight loss and residual weight for the Burgan crude oil at $25^{\circ} \mathrm{C}$ and air flow of $1000 \mathrm{round} / \mathrm{min}$

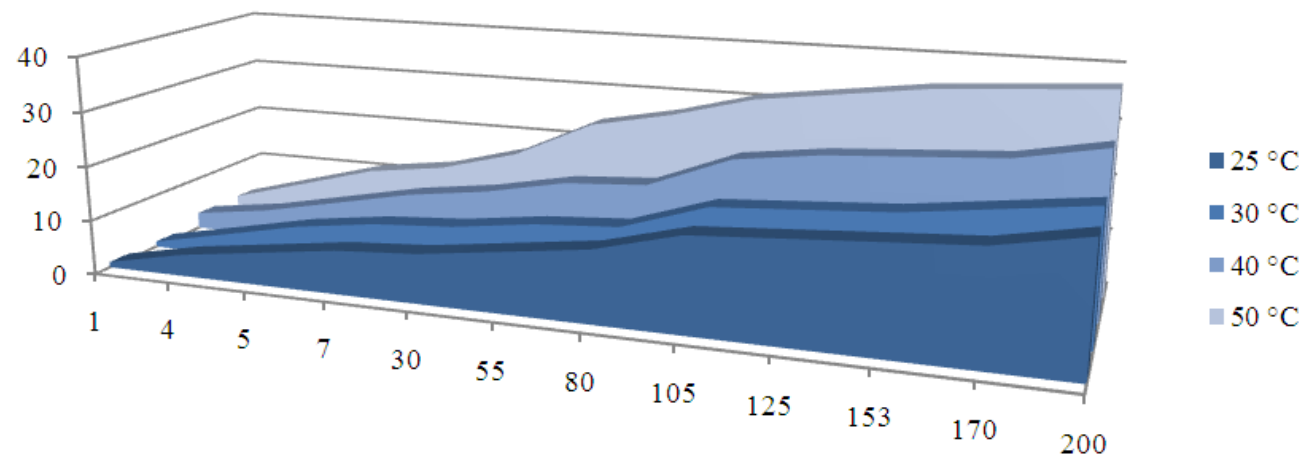

Fig. 5: Cumulative percent loss from Burgan crude oil at $25,30,40$ and $50^{\circ} \mathrm{C}$ with an air flow of $1000 \mathrm{round} / \mathrm{min}$

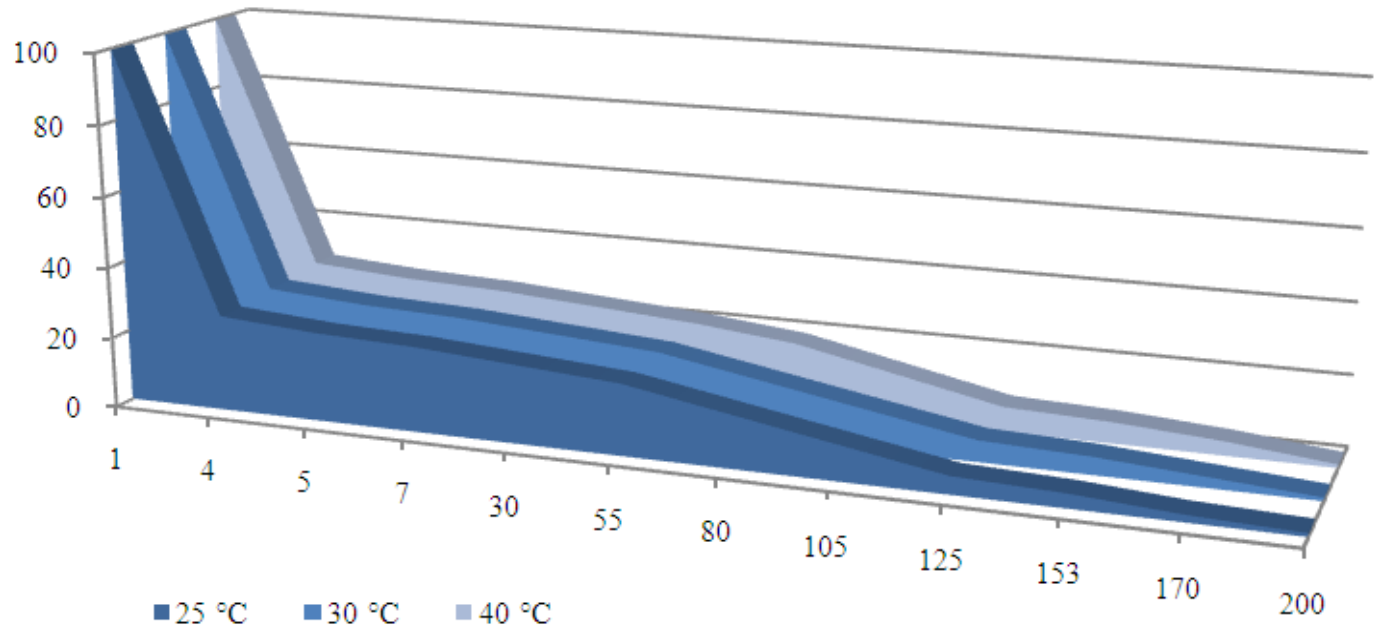

Fig. 6: Percent toluene remaining in the Burgan crude oil as a function of time for evaporation at $30,{ }^{\circ} \mathrm{C}$ and an air flow of 1000 round/m 
Am. J. Environ. Sci., 7 (3): 219-223, 2011

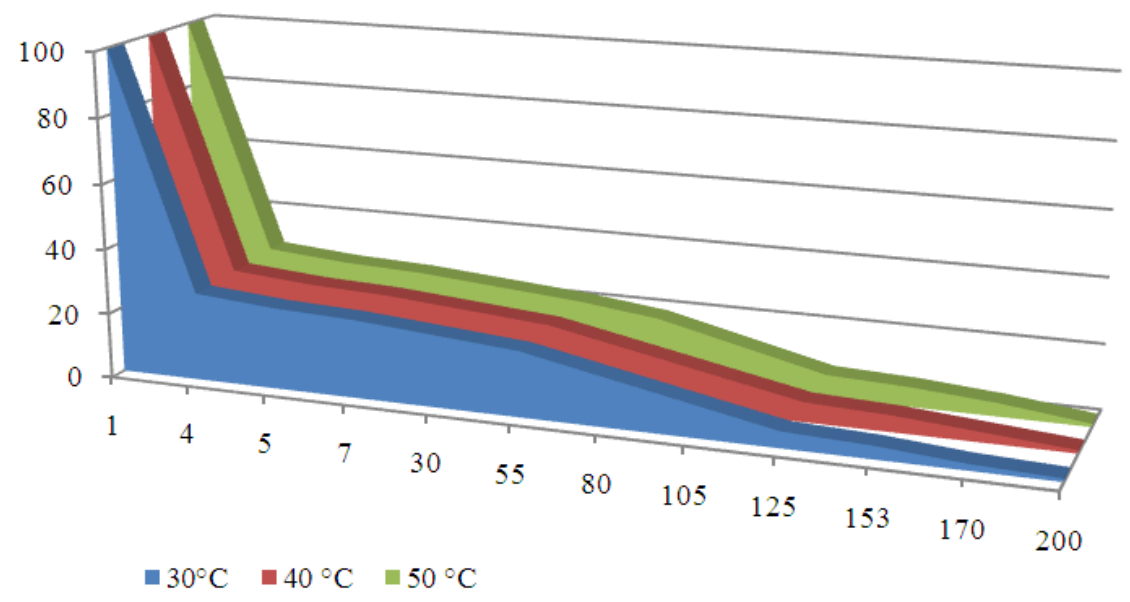

Fig. 7: Percent toluene remaining in the Burgan crude oil as a function of time and temperature for an air blow of $1000 \mathrm{round} / \mathrm{min}$

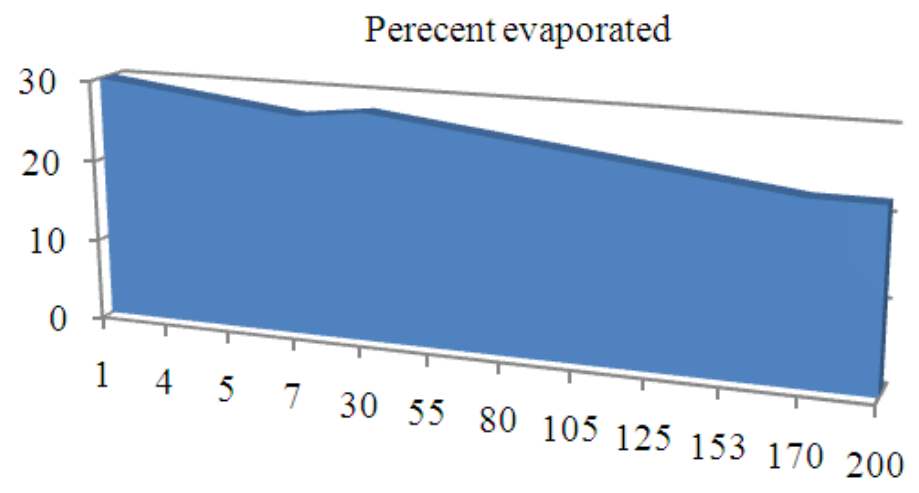

Fig. 8: Decreasing API gravity with progressing evaporation of the Burgan crude oil

Table 1: Percentage weight loss from Burgan oil, Kuwait at selected temperatures and time with an flow of $1000 \mathrm{round} / \mathrm{min}$

\begin{tabular}{llll}
\hline Temperature $\left({ }^{\circ} \mathrm{C}\right)$ & $8 \mathrm{~h}$ & Time $104 \mathrm{~h}$ & $200 \mathrm{~h}$ \\
\hline 25 & 13.07 & 20.47 & 25.68 \\
30 & 14.40 & 21.59 & 25.74 \\
40 & 16.76 & 26.77 & 31.86 \\
50 & 17.06 & 29.91 & 36.60 \\
\hline
\end{tabular}

Table 2: Changes in density, API gravity and viscosity of the Burgan crude oil with progressing evaporation

\begin{tabular}{llll}
\hline Temperature $\left({ }^{\circ} \mathrm{C}\right)$ & $8 \mathrm{~h}$ & Time $104 \mathrm{~h}$ & $200 \mathrm{~h}$ \\
\hline Original oil & 0.876 & 30 & 65.30 \\
12.9 & 0.893 & 27 & 120.4 \\
20.0 & 0.904 & 25 & 132.5 \\
30.0 & 0.922 & 22 & 300.5 \\
\hline
\end{tabular}

Vapor pressure increases with temperature and as a consequence evaporation occurs more rapidly at higher temperatures. This trend is illustrated by the rates of evaporation for toluene at $24,30,40$ and $50^{\circ} \mathrm{C}$ shown in Fig. 7.
Physical changes during evaporation: The physical characteristics of degraded oil can be important in controlling its behavior in the natural system. Density and viscosity are particularly significant and we have documented changes in these properties as the Burgan oil lost light ends by evaporation. The analytical procedures for determining density and viscosity need larger volumes than those required for gas chromatography and evaporation experiments were carried out with $17 \mathrm{~mL}$ Burgan oil samples at a room temperature of $25^{\circ} \mathrm{C}$. These samples were periodically stirred during the evaporation to ensure homogeneity. Separate samples were used for each of the different percentages evaporated. Viscosity was determined with a cone and plate viscometer and density obtained with a hydrometer. The decreasing API gravity (increasing density) for the evaporating oil is shown in Fig. 8 and measured values for density and viscosity are summarized in Table 2. 
For a particular number of carbon atoms, different compound types have different vapor pressure at a given temperature and so evaporative loss depends on compound type. For example, in compounds with seven carbon atoms, the $\mathrm{C} 7$ normal alkane is lost more rapidly than the methylcyclohexane, which is in turn lost more rapidly than the aromatic toluene. A similar evaporation trend of normal alkane > naphthenes> aromatics is also seen for the six carbon compounds. Laboratory simulations with the Burgan crude oil have shown that evaporation leads to the loss of light ends, with the normal alkanes being lost more rapidly than other compound types. While gasoline range compounds are eventually removed completely, larger molecules remain. The composition of the degraded oil sin the southern "oil lakes" of Kuwait is consistent with evaporation as the dominant process. Preliminary experiments with aerobic bacteria have shown that they readily remove Burgan long chain n-alkanes from the oil suggesting that biodegradation has not played a significant role. Laboratory studies of water washing using the apparatus described by Lafargue and Barker (1988) demonstrated the preferential removal of gasoline range hydrocarbons from the Burgan crude oil, but for a given carbon number water washing removes aromatics preferentially whereas evaporation removes $\mathrm{n}$-alkanes. In the oil from the desert the gasoline range hydrocarbons have been completely removed so it is not possible to use these differences to recognize the specific degradation mechanism. However, with an average rainfall of only $155 \mathrm{~mm} / \mathrm{year}$, water washing does not seem to have been a major factor.

Although the evaporation experiments have stressed the Burgan crude oil from Kuwait, similar results have been obtained for Venezuelan oil from the Bolivar November Coastal Fields and it seems likely that many of the conclusions from the reported studies have wide applicability. This could be of significance in tracing pollutants to their source. For example, oil from an open storage tank may have experienced considerable evaporative loss before being spilled into an aqueous system where other processes, notably water washing and biodegradation, are effective. These effects need to be documented in correlating an oil spill to its original source.

\section{CONCLUSION}

It $\mathrm{s}$ seems to be that from the reported studies it have wide Applicability. This could be of significance in tracing pollutants to their source. For example, oil from an open storage tank may have experienced considerable evaporative loss before being spilled into an aqueous system where other processes, notably water washing and biodegradation, are effective. These effects need to be documented in correlating an oil spill to its original source.

\section{REFERENCES}

Corinan, J., 1984. Biodegradation of Crude Oils in Reservoirs. In: Advances in Petroleum Geochemistry, Brooks, J. and D. Welte (Eds.). Academic Press, London, ISBN: 0120320010, pp: 299-330.

Lafargue, E. and C. Barker, 1988. Effect of water washing on crude oil composition. AAPG Bull., 72:

263-276.

http://www.osti.gov/energycitations/product.biblio. jsp?osti_id=6631982.

Obuekwe, C.O., Z.K..al-Jadia and E.S. Al-Saleha, 2008 Hydrocarbon degradation in relation to cell-surface hydrophobicity among bacterial hydrocarbon degraders from petroleum-contaminated Kuwait desert environment. Int. Biodeteriorat. Biodegradat., 63: 273-279. DOI: 10.1016/J.IBIOD.2008.10.004

Olajide, P.O. and L.B. Ogbeifun, 2010. Hydrocarbon biodegrading potentials of a Proteus vulgaris strain isolated from fish samples. Am. J. Applied Sci., 7: 922-928. DOI: 10.3844/ajassp.2010.922.928

Palmer, S.E., 1993. Effect of Biodegradation and Water Washing on Crude Oil Composition. In: Organic Geochemistry, Engel, M.H. and S.A. Macko (Eds.). Springer, New York, ISBN-10: 0306443783, pp: 511-535.

Satoa, S. A. Matsumuraa, Y. Urushingawaa, M. Metwallyb and S. Al-Muzainib, 1998. Structural analysis of weathered oil from Kuwait's environment. Environ. Int., 24: 77-87. DOI: 10.1016/S0160-4120(97)00123-2 